\title{
Boom nas vendas de autoveículos via crédito farto, preços baixos e confiança em alta: o caso de um ciclo?
}

\author{
Fábio Augusto Reis Gomes* \\ Fabio Maciel Ramos ${ }^{* *}$
}

RESUMO - A proposta deste trabalho é contribuir para o debate acerta dos primeiros efeitos da crise de crédito mundial na economia brasileira. Seus primeiros efeitos já podem ser observados nos números de outubro referentes a vendas de veículos, crédito ao consumidor e expectativas para o futuro próximo. Para esta análise, lançou-se mão da ferramenta dos Vetores Auto-Regressivos (VAR) de forma a estimar os impactos de uma alta (ou queda) do crédito, dos preços e da confiança nas vendas de automóveis. A conclusão é de que as variáveis escolhidas são relevantes, sobretudo o volume de crédito. Este escasseando, as vendas de automóveis não só devem, como já estão, de fato, em fase de contração.

Palavras-chave: Indústria automobilística. Vendas de veículos. Crédito pessoas-físicas. Confiança do consumidor. Confiança do empresário.

\section{INTRODUÇÃO}

A crise econômica é uma realidade. Suas causas foram amplamente discutidas. Resta saber suas conseqüências. Mais especificamente, queremos saber como a economia brasileira reagirá à crise. Obviamente esta é uma questão muito ambiciosa e, como um exercício preliminar, examinaremos a evolução da venda de automóveis. A relevância desta variável pode ser explicada por sua importância econômica: a indústria automobilística responde por $1 / 4$ do produto industrial e pouco mais de $5 \%$ do produto total, considerados apenas os impactos diretos ${ }^{1}$. O setor é considerado um bom termômetro da economia por conta de suas ligações com outras atividades, sejam os seus insumos como também os serviços derivados (metalurgia, autopeças, revendas, manutenção, etc.). Ou seja: por seus links para trás e para frente, seguindo a literatura clássica dos encadeamentos setoriais ${ }^{2}$ (Hirschman, 1958).

Antes de proceder à compra de um bem durável, em geral de valor unitário razoavelmente elevado, o consumidor analisa muitas variáveis. Sua renda presente e suas expectativas para o futuro. Analisa também o preço do bem desejado não apenas

\footnotetext{
* Doutor em Economia pela Escola de Pós-Graduação de Economia da Fundação Getúlio Vargas/RJ. Professor em tempo integral do IBMEC - São Paulo. Endereço Eletrônico: fabioarg@isp.edu.br

** Economista. Analista da Quest Investimentos. Endereço Eletrônico: fmramosbr@yahoo.com.br

${ }^{1}$ IBGE Contas Nacionais 2007 e Anfavea.

2 O IBGE divulgou recentemente uma nova Matriz de Insumo-Produto (2000-05), na qual é possível depreender índices de ligação entre setores e a importância da automobilística.
} 
individualmente, mas em comparação com outros bens. E, analisa também as condições de crédito. Então podemos tomar algumas medidas para estudar estas conexões.

As expectativas do consumidor com respeito ao futuro podem ser medidas, em princípio, por um índice de confiança. Se a confiança do consumidor é elevada, ele está mais propenso a se endividar. Do contrário, pode haver uma retração na demanda. Como expectativa é uma variável foward-looking, o volume negociado de carros tende a antecipar movimentos futuros da economia.

O volume de crédito emprestado é também fundamental, pois além de possibilitar a compra de bens mais caros, ele reflete também as expectativas das instituições financeiras. Se uma instituição antecipa pioras na economia e, por conseguinte, espera uma taxa de inadimplência maior, a decisão mais conservadora é reduzir o crédito, elevando o seu custo ou mesmo por meio de estabelecimento de cotas.

Por fim, o preço também deve ser importante. O IPCA reflete as variações no custo de vida do consumidor, levando em conta uma cesta ampla de produtos. Porém, é possível utilizar um de seus subitens: automóvel novo. A demanda por automóveis frente a outros bens - duráveis ou não - deve ser inversamente relacionada ao preço relativo automóveis/IPCA.

\section{A EVOLUÇÃO DAS VENDAS DE AUTOVEÍCULOS E SEUS DETERMINANTES}

A evolução das vendas foi analisada por meio da série de unidades comercializadas de autoveículos $^{3}$ de origem nacional e importada. A série é disponibilizada tanto pela ANFAVEA como pela FENABRAVE. O volume de crédito para pessoas físicas, em milhões de reais, tem como fonte o Banco Central. Com relação aos preços, o IPCA e o subitem “Automóvel Novo" têm como base dezembro de 1993. As séries foram obtidas para o período dezembro de 1994 a outubro de 2008. Todas estas variáveis foram coletadas junto ao IBGE (serviço SIDRA), Banco Central e IPEADATA.

Por fim, o índice de confiança é calculado trimestralmente pela FGV e foi mensalizada pelos autores. Foram testadas séries mensais de outras instituições (CNI, Fecomércio/SP), porém estas padeceram da limitação do número de observações e/ou guardam outros problemas metodológicos. Optou-se pela série de expectativas do empresário

\footnotetext{
3 Automóveis, comerciais leves, caminhões e ônibus.
} 
para a demanda interna. Para maiores detalhes sobre o cálculo das séries, em termos reais, dessazonalizadas e/ou mensalizadas, veja o apêndice.

Após o boom inicial pós-plano real, as vendas de veículos decresceram com a crise mexicana em 1995 e, após uma ligeira recuperação em 1996, estas declinaram até o final de 1998 em decorrência das sucessivas crises externas: coreana, russa e, finalmente, a brasileira. No começo de 1999 houve a mudança do regime cambial, porém, apenas a partir de 2000 a economia brasileira experimentou outra fase de expansão nas vendas (e da economia como um todo). O crescimento verificado em 2000 não perdurou e surgiu a expressão do Brasil e seus "vôos de galinha". Em 2001 houve o racionamento energético e, pouco depois, o estouro da bolha da Internet (NASDAQ) e os atentados terroristas nos EUA.

O ano de 2002 prometera algum alento, porém a primeira candidatura do atual presidente ocorreu com grande desconfiança e, daí, restrições na oferta de crédito e nas vendas de veículos (somados a outros problemas como câmbio em depreciação e inflação em alta).

Então, com a $1^{\mathrm{a}}$ eleição do presidente Lula e bom comportamento dos mercados internacionais, recuperação da confiança na economia e melhora nos termos de troca do comércio exterior brasileiro, as vendas passam a se expandir continuamente. O movimento ganha fôlego renovado a partir de 2006, com a intensificação da alta das commodities exportáveis, apreciação cambial, inflação baixa e melhora dos salários reais e do perfil do emprego.

O comportamento do nível das vendas, em milhares de unidades, pode ser verificada pelo Gráfico 1, que apresenta a série efetiva e ajustada para sazonalidade. GRÁFICO 1 - VENDAS DE AUTOVEÍCULOS (MILHARES UNIDADES/MÊS - AJUSTE SAZONAL E
FILTRO)

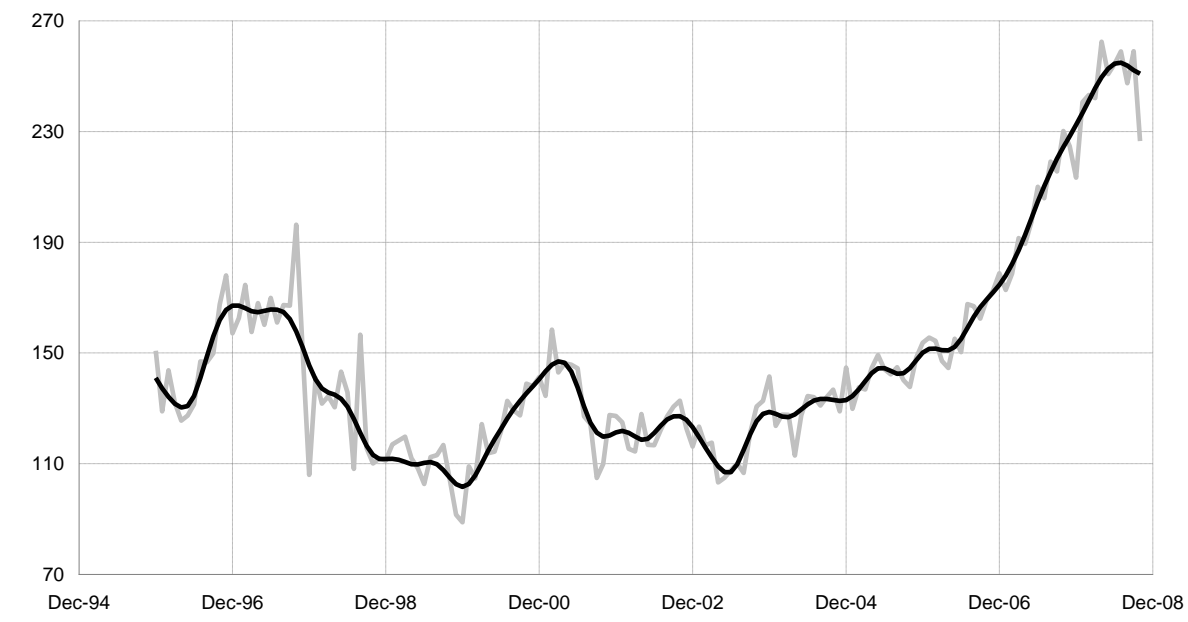

FONTE: Anfavea. Elaboração dos autores. 
Uma variável-chave para a explicação da expansão das vendas é a oferta de crédito disponível e tomado para e pelas pessoas físicas. A oferta de crédito é reduzida em momentos de crise (1997/98, 2001/02) e expandida em momentos de boom (final de 1995, 2000, 2004/08). E aqui entra um ponto muito relevante: até que ponto a atual crise de liquidez pode contrair o crédito da economia e implicar, no caso das famílias, em menor consumo de veículos novos. Os atuais 'feirões' de automóveis com o expressivo número de peças publicitárias veiculadas sugerem que o efeito negativo nas vendas existe. Em outubro especificamente, as vendas declinaram $10 \%$ na margem.

A relação entre as vendas e o crédito real pode ser acompanhada pelo Gráfico 2. A primeira impressão que se tem é a de precedência temporal das vendas em relação ao crédito. É necessário lembrar, contudo, que temos aqui o volume total de crédito, ou seja, um estoque. Este inclui, por exemplo, refinanciamentos. Uma melhor medida seriam as novas concessões. Porém, esta série está disponível apenas a partir de meados de 2000.

Ainda pelo gráfico 2, depreendemos uma perda de ritmo ao final do $3^{\circ}$ trimestre deste ano. Até o momento da confecção deste trabalho os números de crédito com referência a outubro não estavam disponibilizados. Ainda assim, a inferência que se tem é a de brusco arrefecimento.

GRÁFICO 2 - VENDAS DE AUTOMÓVEIS E VOLUME DE CRÉDITO ÀS PESSOAS FÍSICAS*. VARIAÇÃO MENSAL INTERANUAL (\%)

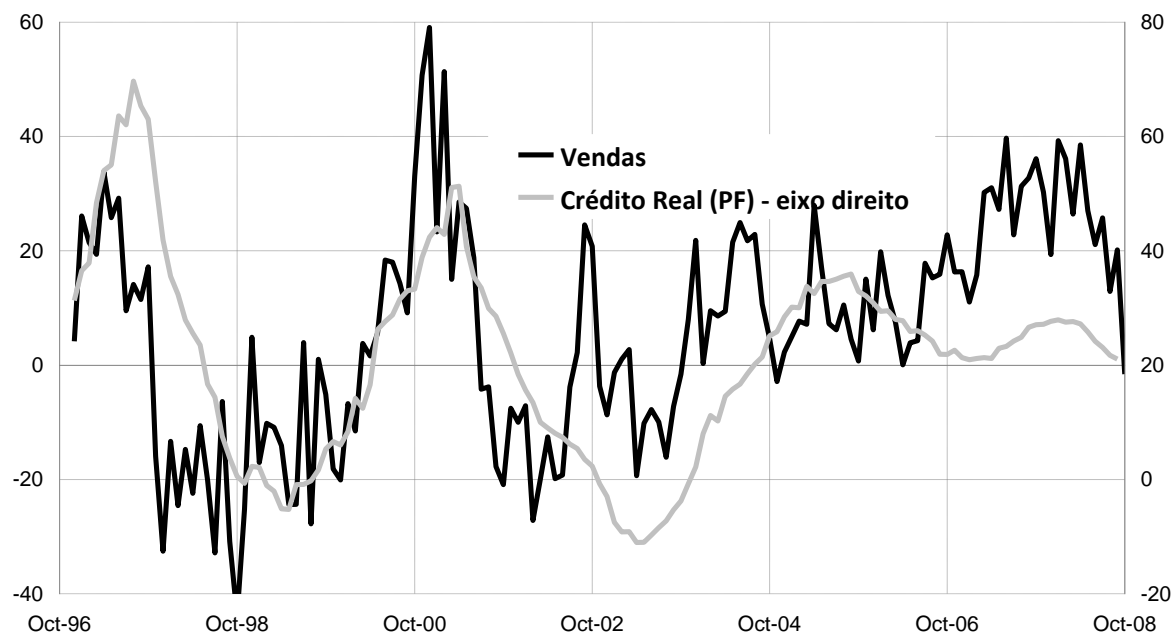

FONTE: IBGE, BCB e Anfavea. Elaboração dos autores.

(*) Volume total às pessoas físicas. Números dessazonalizados e deflacionados (out/08 - IPCA).

Outra variável analisada é a da confiança ou expectativas dos consumidores. Por conta de diversos problemas metodológicos - descritos no apêndice -, usamos como variável proxy a confiança do empresário quanto a demanda doméstica, indicador cuja coleta pela FGV já é tradicional e remonta ao final da década de 1970. 
GRÁFICO 3 - VENDAS DE AUTOVEÍCULOS E ÍNDICE DE CONFIANÇA* (TAXA MENSAL INTERANO E ÍNDICE FILTRADO)

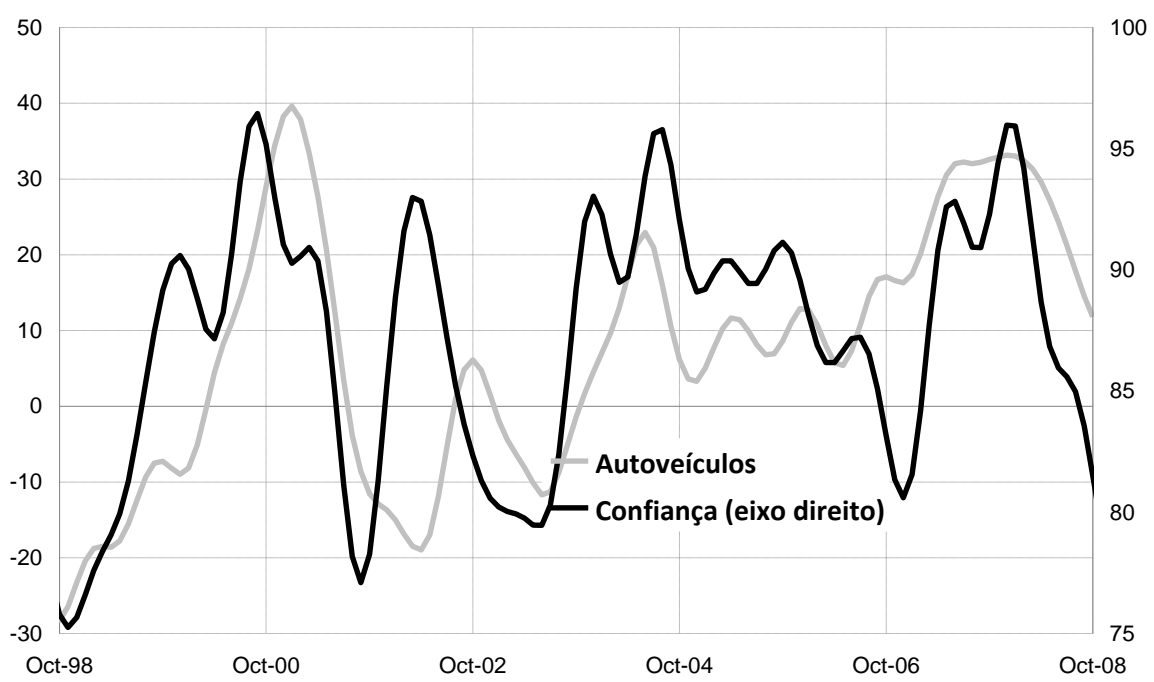

FONTE: Anfavea e FGV. Elaboração dos autores.

(*) Ajuste sazonal X-12 RegARIMA. Séries filtradas para sazonalidade e irregularidades. Índice de Confiança do Empresário sobre a Demanda Interna Futura. Séries 'Antiga' e 'Nova' encadeadas e mensalizadas.

Com dados até outubro, depreendemos do Gráfico 3 que não apenas as vendas de automóveis (e provavelmente o crédito de outubro), mas também a confiança do empresário (e decerto do consumidor) estão em baixa. É mais uma sugestão de que a boa fase dos últimos anos pode estar se encerrando. Pela velocidade das variáveis analisadas, talvez de forma dramática.

Por fim, outra variável que deve estar relacionada ao mercado de automóveis é o preço relativo automóveis contra IPCA. A sugestão é a de que preços relativos menores de automóveis estão ligados a maiores vendas. No Gráfico 4 apresentamos a evolução desta variável.

Exceção feita aos períodos de grande depreciação cambial - e aumento dos preços tradables como automóveis -, o preço automóvel/IPCA caiu quase continuamente desde 1996, sobretudo a partir do final de 2004. Não deve ser à toa que simultaneamente ao aumento das vendas, expansão do produto e aumento dos termos de troca da economia, ocorreu apreciação cambial e queda nos preços dos bens duráveis. A suposição é a de relação inversa entre esta variável e as vendas. E, mais uma vez, a julgar pelo movimento atual de queda nas commodities e depreciação cambial, um grande momento da economia brasileira pode estar se encerrando ${ }^{4}$.

\footnotetext{
${ }^{4}$ Nos 12 meses até outubro os preços dos automóveis na ponta do consumidor sobem cerca de 4\%, um tanto abaixo do pouco mais de 6\% do IPCA. Contudo, há 12 meses, havia deflação da ordem de 3\% no segmento.
} 
GRÁFICO 4 - PREÇO RELATIVO: AUTOMÓVEL NOVO / IPCA* (ÍNDICE - BASE 2005 = 100)

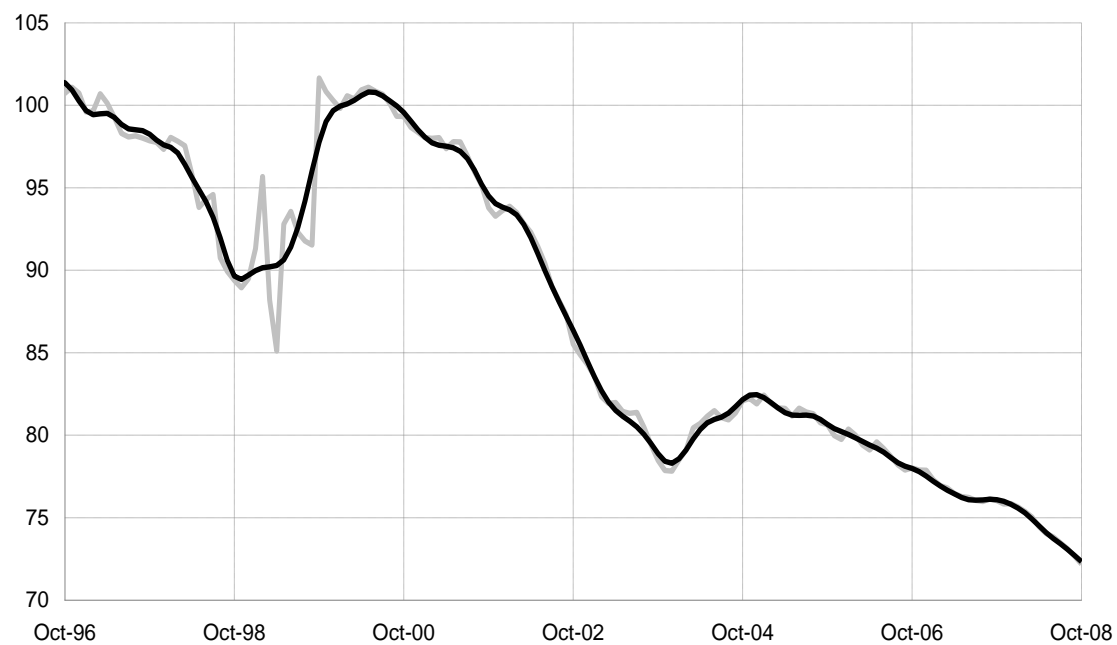

FONTE: IBGE. Elaboração dos autores.

(*) Ajuste sazonal X-12 RegARIMA.

\section{MODELO ECONOMÉTRICO}

Para examinar o impacto das expectativas, volume de crédito e preço relativo de carros sobre as vendas foi lançado mão de um modelo de vetores auto-regressivos (VAR). Para maiores detalhes sobre a construção deste modelo, veja apêndice.

Basicamente, foi utilizado o modelo VAR, pois ele consegue medir como a variável venda de automóveis responde a choques nas variáveis explicativas 'crédito às pessoas físicas', 'preço relativo automóveis-IPCA' e 'e expectativas de demanda interna'. Esta análise é chamada de função resposta a impulso (FRI). A figura 1 apresenta a FRI acumulada da venda de carros às demais variáveis.

Dos gráficos abaixo se depreende alguns resultados interessantes e, de certa forma, intuitivos. Outro, com certa reticência.

Primeiro, deve-se lembrar que o eixo horizontal é o tempo decorrido, em meses, após o choque inicial. No eixo vertical, é a resposta da variável 'vendas' em desvios-padrão. Um choque positivo no crédito real ou na confiança gera resposta positiva nas vendas ${ }^{5}$. É o resultado esperado. No caso do crédito, a resposta se dá com rapidez. Em cerca de 6 meses quase todo o choque é absorvido pela variável-resposta (vendas). Finalmente, o preço-relativo não é estatisticamente significativo. Ressalte-se que o resultado é similar sob erros-padrão analíticos (assintóticos) ou estimados por simulações de Monte-Carlo. Antes da conclusão de que o preço relativo não é relevante para a explicação das vendas, o que decerto é precipitado,

\footnotetext{
${ }^{5}$ Observe que em alguns períodos o intervalo de confiança da FRI de choques no crédito real ou na confiança não contém o valor zero. Daí a conclusão que ambos tem impacto positivo sobre as vendas.
} 
deve-se considerar o problema da medida no IPCA (no passado apurado por tabelas de preços), além da dificuldade da avaliação não hedônica ${ }^{6}$.

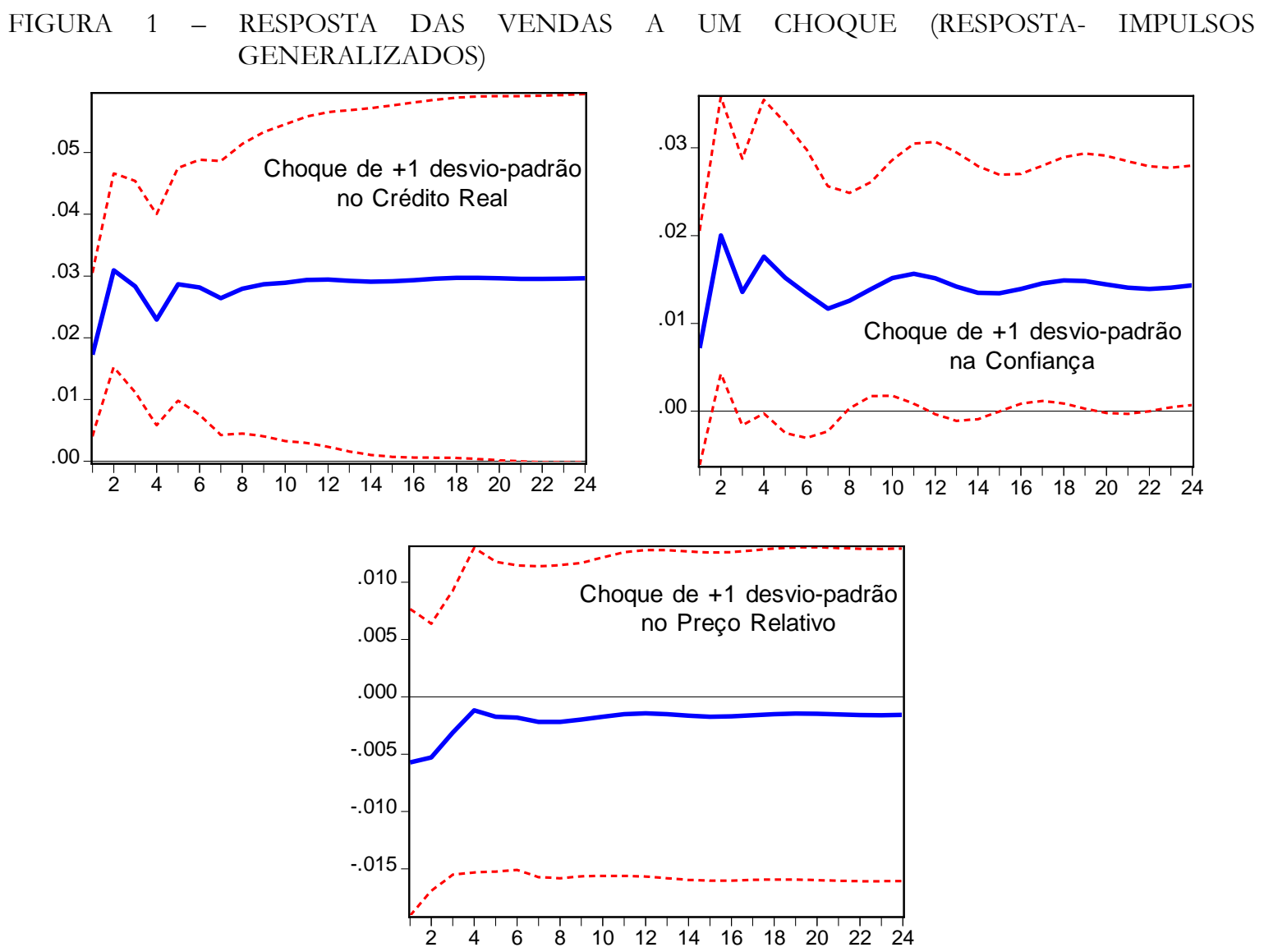

FONTE: Elaboração própria.

Se ao invés de utilizarmos a FRI de um choque ortogonal de magnitude igual ao desvio-padrão, lançarmos mão dos choques simples de um ponto-percentual (limitados econometricamente, porém com resultados mais intuitivos), obtemos resultados semelhantes, apresentados na Figura 2 abaixo.

Um choque de um ponto percentual no crédito gera uma resposta de cerca de 1,5 ponto percentual nas vendas de veículos. Já um aumento da confiança de 1 ponto percentual está associado a um aumento de aproximadamente 0,5 ponto percentual nas vendas de veículos.

\footnotetext{
${ }^{6}$ Ao contrário do BLS-CPI dos EUA, o IBGE prefere não efetuar ajustes de qualidade e funcionalidade do
} produto na coleta do subitem "automóvel novo". A atualização se dá apenas nos modelos de automóveis. 
FIGURA 2 - RESPOSTA DAS VENDAS DE VEÍCULOS A CHOQUES DE 1 PP NAS VARIÁVEIS (RESPOSTA EM PONTOS- PERCENTUAIS)
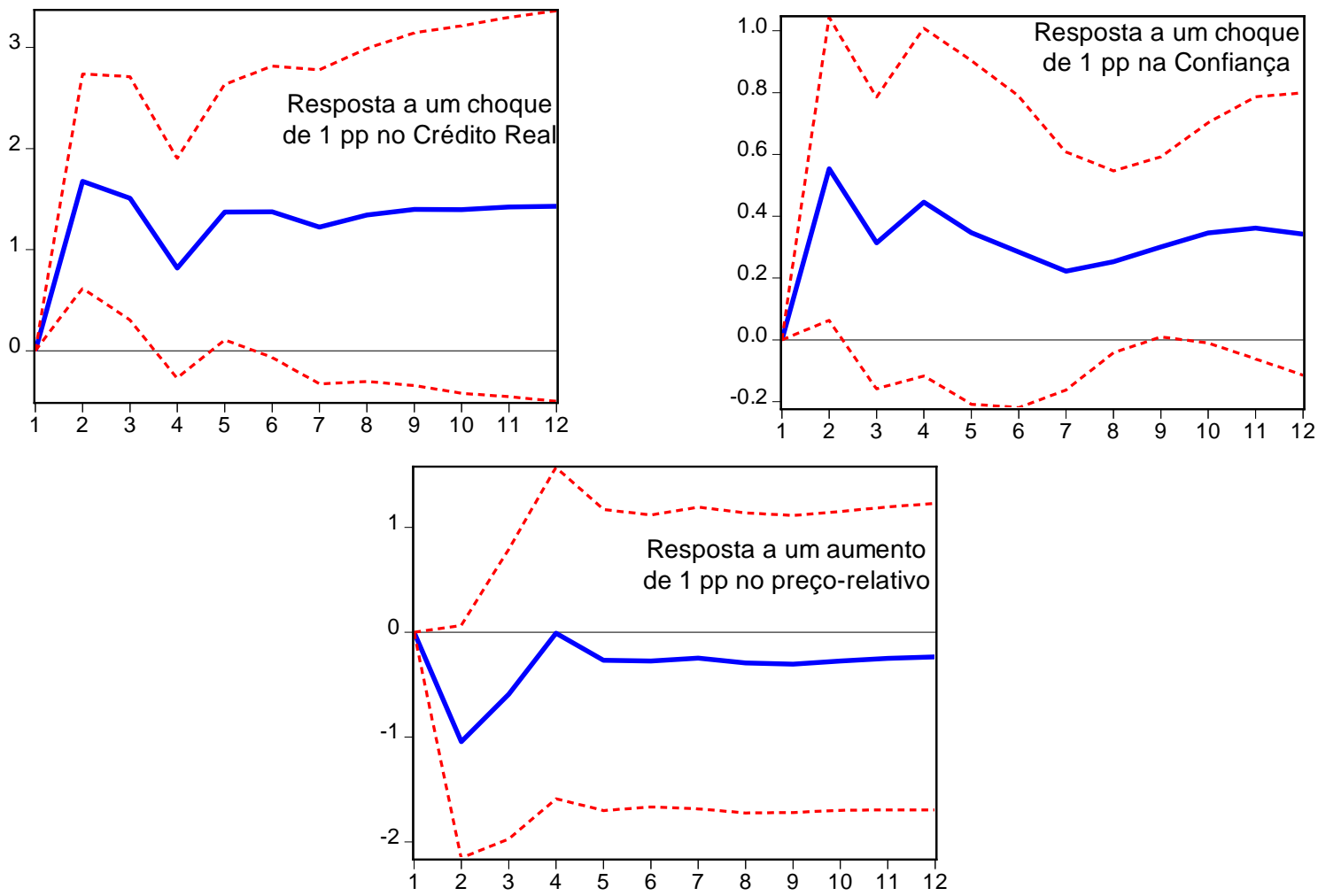

FONTE: Elaboração própria.

\section{CONCLUSÕES}

Neste trabalho procurou-se contribuir para o debate sobre os efeitos da atual crise mundial de crédito na economia doméstica. Como os efeitos devem ser amplos e difusos entre os diversos planos da economia (produção, consumo, poupança, comércio exterior, etc), foi escolhido um setor em específico: o das vendas de automóveis.

Como era esperado, indicadores como confiança e crédito ofertado são importantes drivers na explicação das vendas. Esperava-se que o preço-relativo automóveis/outros preços também fosse importante, porém não foi encontrada uma relação significativa.

O crédito se mostrou uma variável-chave na explicação vendas. Se somarmos as primeiras informações sobre a contração deste, a forte retração das vendas verificada em outubro último e a importância do setor automobilístico na economia, temos fortes evidências do fim de um ciclo de longa expansão - talvez o maior de um dos setores da economia brasileira desde o final dos anos 70 .

Uma primeira sugestão para avanços na área está na incorporação das informações sobre a estrutura do mercado de trabalho - formalização da ocupação via números do MTERAIS/CAGED ou PME - e, também, salário médio real ou massa de salários reais. O 
problema principal será compatibilizar as bases de dados para períodos que remontam o começo do Plano Real. Outra sugestão é trabalhar com a série de 'novas concessões' de crédito ao invés do volume de crédito total. A limitação estará na base, que se iniciou apenas em meados de 2000.

\section{REFERÊNCIAS}

HAMILTON, J. Time Series Analysis. Princeton University Press, 1994.

HIRSCHMAN, A. The strategy of economic development. Yale University Press, 1958.

PESARAN, M.; SHIN, Y "Generalized Impulse Response Analysis in Linear

Multivariate Models", Economics Letters, 58, 1998. P. 17-29.

\section{APÊNDICE}

\section{BASE DE DADOS}

Vendas de autoveículos: soma de automóveis, comerciais leves, caminhões e ônibus. A fonte primária dos dados é a Anfavea (associação das montadoras) ou a Fenabrave (associação das concessionárias). Os números foram ajustados sazonalmente pelos autores, seguindo instruções do IBGE em sua Pesquisa Mensal do Comércio (PMC), pelo método X12 RegArima Multiplicativo Automático, com correções para Carnaval, Corpus-Christi e diasúteis. A fonte secundária dos números é o IPEADATA ou BCB. Foi tomada a série entre $\mathrm{dez} / 93$ e out $/ 08$.

Crédito Real: volume nominal de crédito às pessoas físicas na média dos dias úteis. A fonte primária e secundária é o Banco Central (BCB). Os números foram deflacionados pelo IPCA ajustado sazonalmente (mesmo critério das vendas) e foram removidas irregularidades às quais o IPCA mensal está sujeito.

Confiança do Consumidor: apesar do objetivo ser a utilização da Confiança do Consumidor, na verdade foi utilizada a Confiança do Empresário quanto a Demanda Doméstica. Isso por conta da série original de consumidor ser curta (FGV e CNI) ou padecer de muitas alterações metodológicas ou limitação de área de coleta (Fecomércio/SP). Utilizamos, então, os números da Sondagem Conjuntural da FGV. Os números são trimestrais e foram mensalizados pelo método Denton. Depois, ajustados sazonalmente como as outras variáveis. A série foi derivada da seguinte operação: percentual dos empresários que 
acreditam que a demanda estará 'maior', subtraído do percentual daqueles que julgam que será 'menor' e, por fim, dividiu-se este número pelo percentual dos que julgavam a demanda futura próxima 'igual'. A série existe desde o final dos anos 70 , porém utilizaram-se os números entre dez/93 e out/08.

Preço Relativo Automóveis/IPCA: a fonte primária e secundária é o IBGE (serviço gratuito SIDRA). Porém o subitem 'Automóvel Novo' (código 5.102.001) foi extraído por etapas devido as alterações implantadas pelo IBGE em suas Pesquisas de Orçamentos Familiares (POFs). A base dos números índices foi transformada para a média de 2000. Os números foram ajustados sazonalmente tal como as outras séries.

\section{MODELO VAR}

O modelo VAR na forma estrutural pode ser descrito do seguinte modo:

$$
A x_{t}=B_{0}+B_{1} x_{t-1}+B_{2} x_{t-2} \cdots+B_{p} x_{t-p}+C z_{t}+\varepsilon_{t}
$$

em que $x_{t}$ é um vetor de dimensão $4 \times 1$ com a taxa de crescimento das variáveis vendas, crédito, expectativas do consumidor e preço relativo de carros no período t; ${ }^{\varepsilon_{t}}$ é o vetor de choques estruturais (ortogonais) destas variáveis; ${ }_{t}$ são variáveis exógenas, no caso, uma dummy referente a primeira campanha presidencial de Lula, igual a 1 entre agosto de 2002 a janeiro de 2003 e zero nos demais meses. Também foram incluídas dummies para a mudança do regime cambial - Jan/99, Fev/99 e Mar/99 -, sendo a primeira dummy, removida após testes. $A, B_{0}, B_{1}, B_{2}, \ldots, B_{p}, C$ são matrizes de coeficientes desconhecidos.

Estimamos a forma reduzida

$$
x_{t}=A^{-1} B_{0}+A^{-1} B_{1} x_{t-1}+A^{-1} B_{2} x_{t-2} \cdots+A^{-1} B_{p} x_{t-p}+A^{-1} \varepsilon_{t}
$$

A escolha da ordem do VAR, p, foi feita com base nos critérios de informação e nos testes de diagnóstico, em especial, o teste de correlação serial, uma vez que neste contexto tal problema causa viés nas estimativas dos coeficientes. Finalmente, $p=3$.

Por fim, calculamos a função resposta a impulso, $\partial x_{t} / \partial \varepsilon_{t}$, por meio de função resposta a impulso generalizada de Pesaran e Shin (1998). Uma das vantagens deste método é que ele não depende da ordenação das variáveis no VAR, ao contrário da decomposição usual de Cholesky. Para maiores detalhes sobre modelos VAR ver Hamilton (1994). 